\title{
Climatic controls on the stable isotopic composition of precipitation in Northeast Asia
}

\author{
Kwang-Sik Lee ${ }^{1, *}$, Andrew J. Grundstein ${ }^{2}$, David B. Wenner ${ }^{3}$, Man-Sik Choi ${ }^{1}$, \\ Nam-Chil Woo ${ }^{4}$, Dae-Ha Lee ${ }^{5}$ \\ ${ }^{1}$ Korea Basic Science Institute, Eoeun-dong 52, Yusung-gu, Daejeon 305-333, Korea \\ ${ }^{2}$ Department of Geography, and ${ }^{3}$ Department of Geology, University of Georgia, Athens, Georgia 30602, USA \\ ${ }^{4}$ Department of Earth System Sciences, Yonsei University, Seoul 120-749, Korea \\ ${ }^{5}$ Korea Institute of Geoscience and Mineral Resources, Gajeong-dong 30, Yusung-gu, Daejeon 305-350, Korea
}

\begin{abstract}
An examination of oxygen and hydrogen isotopic compositions of precipitation in NE Asia from the IAEA/WMO data set reveals that many sites have a distinct winter-summer seasonal pattern in deuterium excess (d-) values that appears to reflect different climatic conditions. To further understand this pattern, stable isotopic data were obtained for individual rainfall events over a $2 \mathrm{yr}$ period at Jeju Island, Korea. The $\delta^{18} \mathrm{O}$ - and $\delta \mathrm{D}$-values of precipitation at Jeju Island are not dependent upon temperature. However, the deuterium excess values, which range from 3.0 to $40.6 \%$, show a distinct seasonal variation with higher d-values in winter $(>\sim 15 \%)$ and lower values in summer $(\sim 10 \%)$. Such a seasonal variation is closely related to different air masses affecting the island during different seasons: a cold-dry continental polar air mass in winter and a hot-humid maritime tropical air mass in summer.
\end{abstract}

KEY WORDS: Oxygen · Hydrogen · Isotopic composition · Precipitation · Deuterium excess values · Northeast Asia $\cdot$ Jeju Island $\cdot$ Korea

Resale or republication not permitted without written consent of the publisher

\section{INTRODUCTION}

The oxygen and hydrogen isotopic composition of precipitation provides important information on atmospheric circulation and climate change (Ehhalt et al. 1963, Dansgaard 1964, Gat \& Carmi 1970, Yurtsever \& Gat 1981, Lawrence et al. 1982, Gedzelman et al. 1987, Lawrence \& White 1991, Rozanski et al. 1993). In particular, measurement of the ${ }^{18} \mathrm{O} /{ }^{16} \mathrm{O}$ and $\mathrm{D} / \mathrm{H}$ ratios from a set of rainfall samples at a particular site over time provides an estimation of the deuterium excess or d-value, originally defined by Dansgaard (1964) as equal to $\delta \mathrm{D}-8 \delta^{18} \mathrm{O}$. This parameter is generally regarded as the most useful stable-isotope property for characterizing the vapor origin of water (Gat \& Carmi 1970). Low d-values of precipitation reflect slow evaporation at its source region due to high humidity, whereas high d-values reflect fast evaporation at its source region due to low humidity (Clark \& Fritz 1997).
The d-value for a cloud mass is thought to be established during primary evaporation at the site of origin due to kinetic isotope fractionation processes whose magnitude varies due to factors such as relative humidity, wind speed, and the sea surface temperature (e.g. Clark \& Fritz 1997). The d-value is often directly mirrored by the rainfall of the cloud mass, although changes can occur as well. For example, mixing with another moisture source is believed to occur as storm fronts originating in central Europe with d-values of $<12 \%$ migrate SE over the Mediterranean Sea and produce rainfall with d-values of $>18 \%$ in the Levant (Gat \& Carmi 1970). The d-value of precipitation can also decrease due to partial re-evaporation when rain falls in dry environments (Gat \& Dansgaard 1972).

The d-values of rainfall at a site can display a seasonal variation when air masses originate from different locations during different times of the year. Dansgaard (1964), for example, showed from the 1961-62 
IAEA/WMO data set that a seasonal pattern of d-values exists in monthly bulk precipitation in Tokyo, Japan. He noted that all samples from winter had d-values $>14 \%$ and ascribed this to the fact that winter precipitation was dominated by dry continental winds from the northeast collecting moisture from the Sea of Japan. In summer, precipitation in Tokyo had lower $\mathrm{d}$-values, mainly because moisture originated from the southeast in the central Pacific. Published data on the isotopic composition of precipitation in Korea, although scarce, seem to indicate that this same pattern exists to the east. Kim \& Nakai (1988) and Lee \& Chang (1994) present evidence from data collected over separate $1 \mathrm{yr}$ periods that the d-values of precipitation are enriched in winter and depleted in summer. Using the whole IAEA/WMO data set from 1961 to 1987, Rozanski et al. (1993) confirmed the original observations of Dansgaard (1964) and noted that such systematic variations in d-values can be seen in many coastal and continental locations.

We explore this observation further by analyzing selected monthly average precipitation from the IAEA/WMO data set from the NE Pacific, principally from Tokyo and Ryori (Japan), Pohang (Korea), and from selected sites in northern and eastern China. We supplement the existing IAEA/WMO data set with hydrogen and oxygen isotopic data from individual precipitation events during a 2 yr period from May 1995 to May 1997 from Jeju Island, located on the southern tip of the Korean Peninsula.

This new data set provides a means for examining with finer resolution the link between variations in $\mathrm{d}$-values and seasonal variations in air mass type and temperature. Jeju Island has a middle latitude climate and is subject to considerable variations in temperature and humidity throughout the year. In the winter, it is subject to frequent intrusions of cold, dry continental polar air masses, whereas warm, moist maritime tropical air masses are predominant during the summer months. Moisture originates from the north in winter, shifts to the west in the spring and fall, and comes from the southeast in summer (Kwon 1985). Precipitation from these different locations is expected to produce a unique seasonal pattern of d-values that reflect differences in conditions where the moisture originated.

The climate analysis relied on National Centers for Environmental Prediction (NCEP) reanalysis data provided by the NOAA-CIRES (Cooperative Institute for Research in Environmental Sciences) Climate Diagnostics Center, Boulder, Colorado, USA (Kalnay et al. 1996). Seasonal patterns of circulation were generated from long-term monthly averages extending from 1968 to 1996. Temperature, relative humidity, sea-level pressure, precipitable water, and snow water equivalent are daily average data. Both temperature and rel- ative humidity are taken at the $2 \mathrm{~m}$ level. Precipitable water is a vertical integral of atmospheric moisture and is a useful indicator of the total moisture in the air mass. Surface sea temperature (SST) maps use reconstructed Reynolds monthly average SST data (Reynolds 1988). Backward trajectories of air parcels were modeled over a $4 \mathrm{~d}$ period using the hybrid singleparticle Lagrangian integrated trajectory (HYSPLIT) model available from the NOAA Air Resources Laboratory (Draxler 1999). Isobaric trajectories at the $850 \mathrm{mb}$ height were utilized to represent the movement of the larger air mass.

\section{IAEA/WHO DATA FROM NORTHEAST ASIA}

IAEA/WHO stable isotopic data from the IAEA website (http://isohis.iaea.org) for various locations in NE Asia (Fig. 1) are evaluated to examine the temporal and spatial variations in d-values. Monthly data over the years reported from selected sites since 1961 are presented in Fig. 2. This data set is of variable completeness, with Tokyo and Ryori, Japan and Pohang, Korea having the greatest coverage. Data from many stations in China and far eastern Russia were too incomplete for analysis.

All of the data except in Qiqihar, China (Manchuria), show a characteristic pattern of high d-values in winter and lower values in summer (Fig. 2). In Tokyo and Ryori, Japan, d-values show a large range, from -13.3 to $31.7 \%$, and a distinct winter-summer cyclic variation, with high values in winter and low values in summer. Such a seasonal variation (-6.6 to $34.7 \%$ ) is also seen in Pohang, Korea, although it is not quite as distinct as in Japan. Seasonal variations appear to be less distinct in eastern China (Wulumuqi) and almost non existent in Manchuria (Qiqihar). At all sites except Qiqihar, d-values for winter precipitation are generally $>15 \%$. Thus, in East Asia, it appears that seasonal variations in d-values are generally more distinct in coastal areas, although Wulumuqi, in eastern China, is a notable exception.

\section{JEJU ISLAND STUDY}

\subsection{Area of investigation}

Jeju Island is located about $100 \mathrm{~km}$ SW of the Korean Peninsula (Fig. 1) between $33^{\circ} 12^{\prime}$ and $33^{\circ} 34^{\prime} \mathrm{N}$ and is bordered to the west by the Yellow Sea, to the northeast by the Korean Strait and to the south by the East China Sea. Precipitation samples for this study were collected from a meteorological station located at Seongsan on the east side of the island. 
Fig. 1. Map of NE Asia showing locations of IAEA/WMO network sites examined in this study and location of Jeju Island, Korea

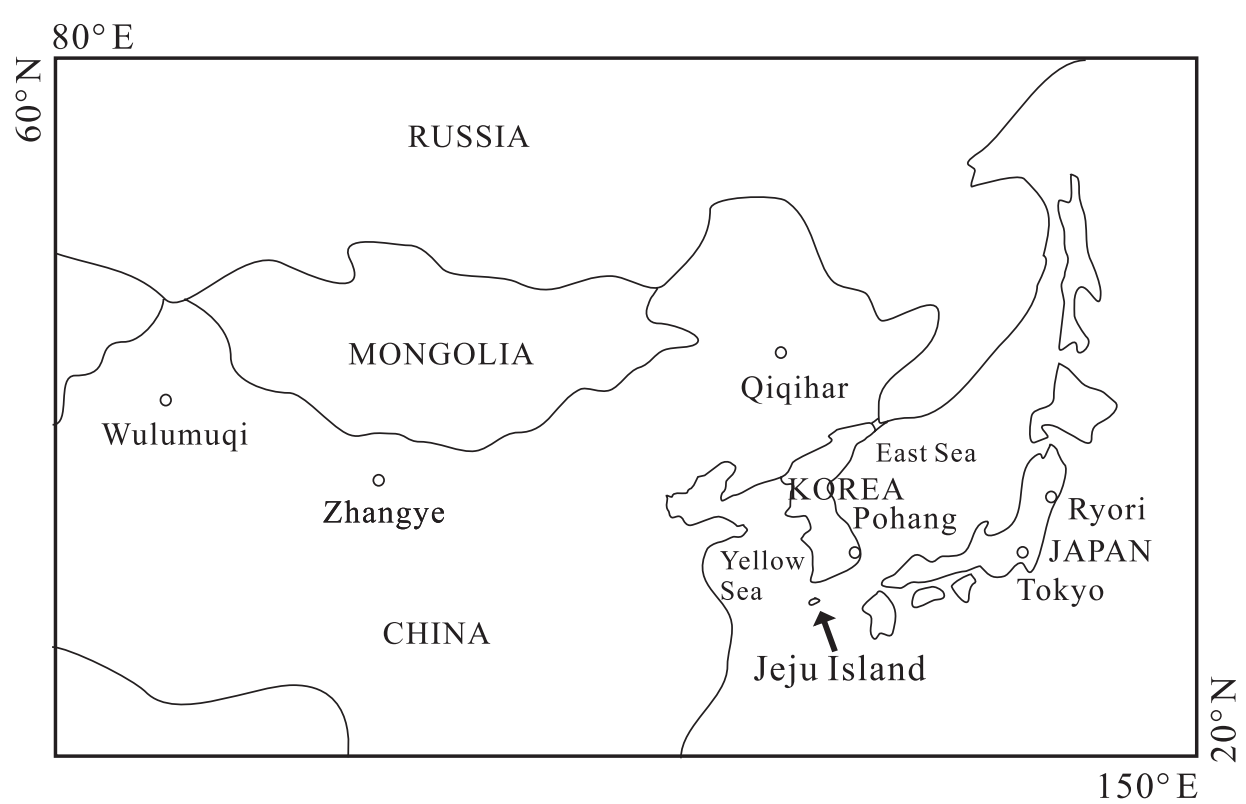

The climate of Jeju Island is dominated by the Asian monsoon wind system that is driven by contrasts in land-sea heating. The seasonal shifts in wind direction produced by the monsoon results in both continental and oceanic influences on the local climate. In the summer, heating of the Asian landmass results in the formation of low pressure centers. Their cyclonic circulation drives a southwesterly flow over the island which brings in warm, moist maritime tropical air masses from the North Pacific (Fig. 3a). During the winter, intense cooling of the Asian continent leads to a strong high pressure center and anticyclonic circulation with winds that direct cold, dry continental polar air masses over Jeju Island (Fig. 3b). This seasonal variation in circulation is reflected in the annual cycles of temperature and precipitation. Long-term average temperatures (1923-1992) indicate a fairly large monthly mean temperature range of over $20^{\circ} \mathrm{C}$ (Fig. 4a). Similarly, average monthly precipitation exceeds $200 \mathrm{~mm}$ in the summer, but less than $50 \mathrm{~mm}$ in the winter (Fig. 4b).

During the study period, monthly average temperatures were near the 70 yr average (Fig. 4a). Precipitation
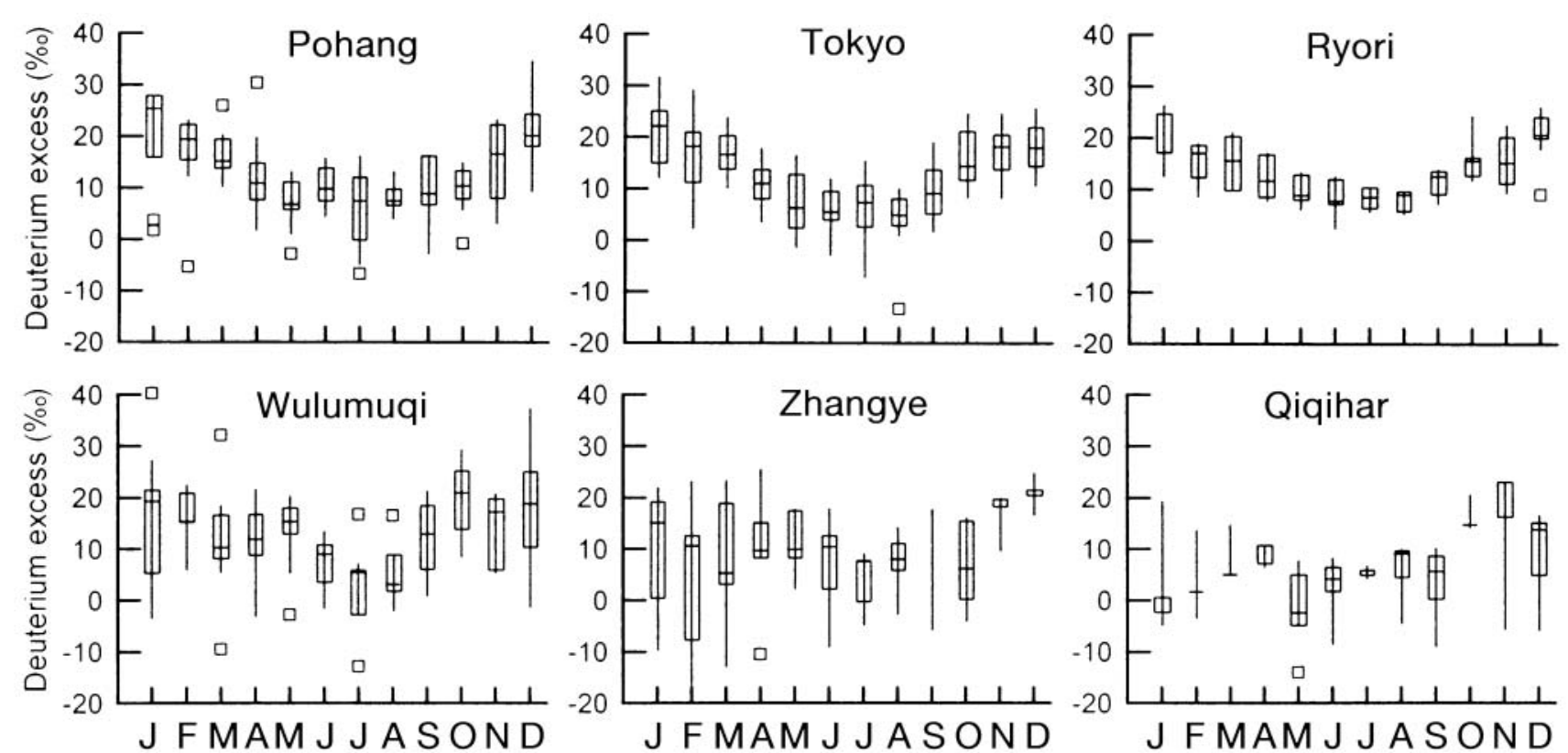

Fig. 2. Seasonal variations of deuterium excess values in precipitation from selected sites in NE Asia listed on the IAEA/WMO network (medians, quartiles and ranges) during 1961 to 1997 . Outliers plotted as squares 

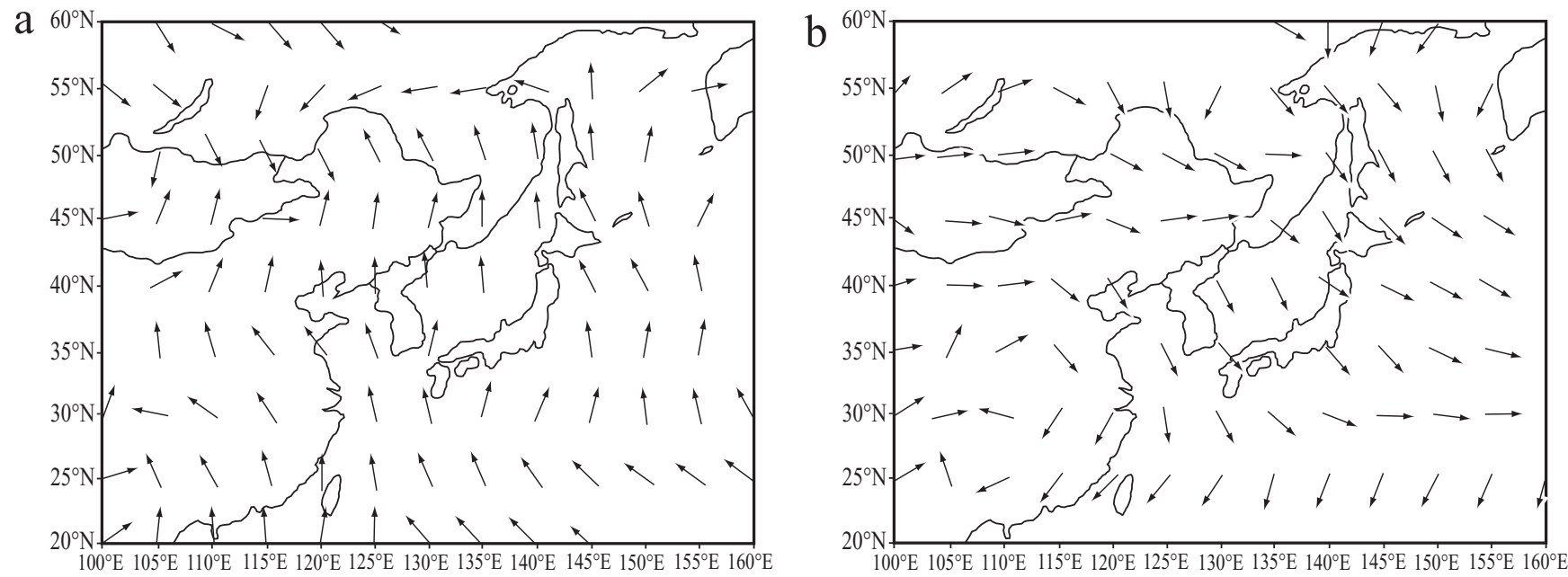

Fig. 3. (a) Long-term mean summer (June to August) surface winds and (b) long-term mean winter (December to February) surface winds

for the first summer was $61 \%$ above normal and $12 \%$ below normal for the second summer (Fig. 4b). Precipitation for the first winter was $32 \%$ below normal and near normal for the second winter. Precipitation for spring and fall was generally higher than normal. Relative humidity averaged $78 \%$ in summers and $63 \%$ in winters.

\subsection{Sampling and analytical methods}

Over 100 precipitation samples were collected during a 2 yr period from May 1995 to May 1997. Samples from

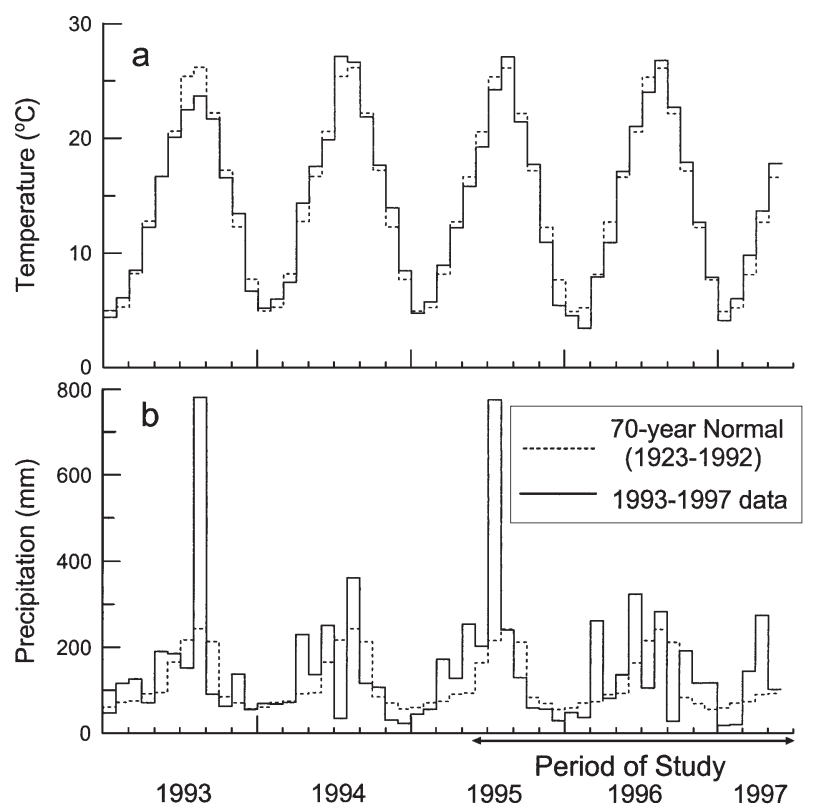

Fig. 4. (a) Monthly average temperatures and (b) total monthly precipitation for the period 1993 to 1997 compared to the 70 -year average at Jeju Island whole and discrete individual rainfall events were collected separately. Precipitation sampling procedures were designed to avoid loss of water via evaporation, by removing samples from the collection apparatus as soon as possible after rainfall, storing precipitation samples in airtight bottles, and keeping the samples refrigerated until analysis. The precipitation sampling procedure is similar to that used by the Global Network for Isotopes in Precipitation (GNIP) except that the samples represent single rainfall events and therefore provide greater resolution. Water samples for oxygen isotopic analyses were prepared by the $\mathrm{H}_{2} \mathrm{O}-\mathrm{CO}_{2}$ equilibration method (Epstein \& Mayeda 1953). About $2 \mathrm{ml}$ of the water sample was equilibrated with tank $\mathrm{CO}_{2}$ gas at $25^{\circ} \mathrm{C}$ and then the $\mathrm{CO}_{2}$ gas was extracted and purified. For deuterium analysis, metallic zinc was used to produce hydrogen gas (Coleman et al. 1982). The oxygen and hydrogen isotopic compositions of the samples were determined using a VG Prism II stable isotope ratio mass spectrometer at the Korea Basic Science Institute. The analytical reproducibility of the $\delta^{18} \mathrm{O}$ - and $\delta \mathrm{D}$-values was \pm 0.1 and $\pm 1 \%$, respectively. All oxygen and hydrogen isotopic analyses are reported in the usual $\delta$ notation relative to V-SMOW, where $\delta=\left(\mathrm{R} / \mathrm{R}_{\mathrm{V} \text {-SMOW }}-1\right) \times 1000$ and $\mathrm{R}$ represents either the ${ }^{18} \mathrm{O} /{ }^{16} \mathrm{O}$ or the $\mathrm{D} / \mathrm{H}$ ratio of the sample and standard, respectively.

\subsection{Variations in $\delta^{18} \mathrm{O}$ and $\delta \mathrm{D}$ composition}

Oxygen and hydrogen isotope data and volumes for individual precipitation events are given in Table 1 and Fig. 5. Also shown are the monthly weighted averages calculated using the equation of Yurtsever \& Gat (1981): $\delta_{\mathrm{WA}}=\sum\left(\mathrm{P}_{\mathrm{i}} \delta_{\mathrm{i}}\right) / \sum \mathrm{P}_{\mathrm{i}}$, where $\delta_{\mathrm{WA}}=$ monthly weighted average isotopic composition, $\mathrm{P}_{\mathrm{i}}=$ precipitation amount 
Table 1. Oxygen and hydrogen isotopic composition of precipitation and meteorological parameters at Jeju Island; $d=\delta \mathrm{D}-8 \delta^{18} \mathrm{O}$

\begin{tabular}{|c|c|c|c|c|c|c|c|c|c|}
\hline $\begin{array}{l}\text { Date } \\
(\mathrm{mo} / \mathrm{d})\end{array}$ & $\begin{array}{l}\delta^{18} \mathrm{O} \\
(\% \circ)\end{array}$ & $\begin{array}{l}\delta \mathrm{D} \\
(\% \circ)\end{array}$ & $\begin{array}{c}\mathrm{d}(\mathrm{mo} / \mathrm{d}) \\
(\% \circ)\end{array}$ & $\begin{array}{l}\text { Amount } \\
(\mathrm{mm})\end{array}$ & $\begin{array}{l}\text { Date } \\
\text { (mo/d) }\end{array}$ & $\begin{array}{l}\delta^{18} \mathrm{O} \\
(\% \circ)\end{array}$ & $\begin{array}{l}\delta \mathrm{D} \\
(\% \circ)\end{array}$ & $\underset{(\%)}{\mathrm{d}(\mathrm{mo} / \mathrm{d})}$ & $\begin{array}{c}\text { Amount } \\
(\mathrm{mm})\end{array}$ \\
\hline 1995 & & & & & \multicolumn{2}{|c|}{1996 continued } & & & \\
\hline $5 / 25$ & -2.3 & -1 & 17.7 & 26.5 & $4 / 14$ & -5.9 & -26 & 20.9 & 13.5 \\
\hline $5 / 28-29$ & -3.3 & -14 & 12.8 & 26.5 & $4 / 15-16$ & -6.2 & -35 & 14.4 & 5.5 \\
\hline $6 / 2-3$ & -7.2 & -48 & 9.7 & 77.5 & $4 / 19$ & -1.2 & 3 & 12.6 & 2.0 \\
\hline $6 / 12-13$ & -5.6 & -37 & 8.2 & 37.5 & $4 / 29-30$ & -3.5 & -9 & 19.0 & 60.0 \\
\hline $6 / 17-18$ & -8.2 & -55 & 10.7 & 16.5 & $5 / 4$ & -3.9 & -18 & 13.2 & 43.5 \\
\hline $6 / 21$ & -8.2 & -62 & 3.7 & 28.5 & $5 / 7-8$ & -3.2 & -9 & 16.6 & 41.5 \\
\hline $6 / 25$ & -8.0 & -61 & 3.2 & 2.0 & $5 / 27$ & -2.4 & -15 & 4.2 & 1.5 \\
\hline $7 / 1-3$ & -11.2 & -77 & 12.4 & 317.5 & $5 / 28-29$ & -8.1 & -51 & 13.8 & 51.0 \\
\hline $7 / 4-5$ & -13.5 & -105 & 3.0 & 38.0 & $6 / 3-4$ & -6.8 & -46 & 8.4 & 24.5 \\
\hline $7 / 6-8$ & -9.0 & -64 & 8.2 & 272.0 & $6 / 7$ & -1.7 & -3 & 10.6 & 13.0 \\
\hline $7 / 22-24$ & -8.4 & -58 & 9.0 & 151.5 & $6 / 16$ & -3.5 & -21 & 7.0 & 3.0 \\
\hline $8 / 1$ & -5.4 & -36 & 7.5 & 5.5 & $6 / 17$ & -8.0 & -55 & 8.7 & 10.0 \\
\hline $8 / 18$ & -4.4 & -30 & 5.3 & 0.5 & $6 / 19-20$ & -10.4 & -70 & 13.2 & 81.0 \\
\hline $8 / 19-21$ & -6.7 & -43 & 10.3 & 78.5 & $6 / 21-25$ & -10.8 & -71 & 15.3 & 166.5 \\
\hline $8 / 22-23$ & -9.3 & -67 & 7.3 & 25.5 & $6 / 27-29$ & -8.0 & -54 & 10.3 & 26.5 \\
\hline $8 / 24$ & -4.6 & -29 & 8.0 & 4.0 & $7 / 2-4$ & -5.6 & -41 & 3.6 & 8.0 \\
\hline $8 / 26$ & -9.3 & -64 & 10.4 & 11.5 & $7 / 10-12$ & -4.6 & -27 & 10.0 & 54.0 \\
\hline $8 / 29$ & -10.4 & -70 & $\begin{array}{l}10.4 \\
13.1\end{array}$ & 84.5 & $7 / 13$ & -4.2 & -23 & 10.8 & 35.0 \\
\hline $8 / 30$ & -5.2 & -28 & 13.5 & 29.5 & $7 / 14$ & -4.7 & -31 & 6.3 & 2.0 \\
\hline $9 / 3$ & -8.6 & -64 & 5.0 & $\begin{array}{r}29.0 \\
6.5\end{array}$ & $7 / 27$ & -2.5 & -14 & 6.0 & 6.0 \\
\hline $9 / 10$ & -4.2 & -23 & 10.7 & 3.0 & $8 / 10$ & -4.1 & -20 & 13.0 & 12.5 \\
\hline $9 / 14$ & -7.3 & -51 & 7.5 & 6.0 & $8 / 19-20$ & -7.7 & -51 & 10.3 & 35.5 \\
\hline $9 / 21-23$ & -7.9 & -46 & 16.8 & 116.0 & $8 / 21$ & -10.3 & -75 & 7.6 & 67.0 \\
\hline $9 / 30-10 / 1$ & -7.1 & -46 & 11.1 & 22.0 & $8 / 24$ & -2.2 & -12 & 5.2 & 2.0 \\
\hline $10 / 3$ & -5.8 & -36 & 10.4 & 7.5 & $8 / 28$ & -9.0 & -62 & 9.7 & 68.0 \\
\hline $10 / 5$ & -5.5 & -37 & 6.8 & 2.5 & $8 / 30$ & -4.1 & -19 & 13.7 & 28.0 \\
\hline $10 / 7-8$ & -3.5 & -21 & 6.7 & 1.0 & $8 / 31$ & -8.0 & -53 & 11.2 & 72.0 \\
\hline $10 / 15$ & -3.5 & -10 & 17.8 & 17.0 & $9 / 8-9$ & -4.1 & -24 & 8.5 & 21.0 \\
\hline $10 / 24$ & -4.7 & -13 & 24.5 & 11.0 & $9 / 29-30$ & -5.0 & -24 & 16.1 & 7.5 \\
\hline $11 / 1-2$ & -2.8 & 4 & 26.5 & 2.5 & $10 / 2-3$ & -4.8 & -13 & 25.4 & 6.5 \\
\hline $11 / 7-8$ & -3.3 & -4 & 22.6 & 3.5 & $10 / 6-8$ & -7.4 & -41 & 18.2 & 26.5 \\
\hline $11 / 13-14$ & -9.3 & -55 & 19.2 & 34.0 & $10 / 12$ & -2.9 & 8 & 30.7 & 8.5 \\
\hline $11 / 23$ & -6.5 & -23 & 28.7 & 12.5 & $10 / 31$ & -6.1 & -16 & 33.0 & 151.0 \\
\hline $11 / 24$ & -9.3 & -43 & 31.8 & 5.5 & $11 / 1-2$ & -7.3 & -38 & 20.0 & 34.0 \\
\hline $12 / 5-6$ & -8.0 & $\begin{array}{l}75 \\
-29\end{array}$ & 35.0 & 22.0 & $11 / 4-5$ & -4.1 & -10 & 22.7 & 50.0 \\
\hline $12 / 7-8$ & -7.0 & -27 & 29.3 & 5.5 & $11 / 7-9$ & -4.3 & -9 & 25.8 & 19.5 \\
\hline $12 / 24-25^{\text {a }}$ & -5.2 & -11 & 30.4 & 1.9 & $11 / 29-30^{\mathrm{a}}$ & -7.1 & -25 & 31.8 & 12.8 \\
\hline $12 / 28$ & -3.6 & -4 & 25.0 & 1.5 & $12 / 4-5$ & -7.9 & -23 & 40.6 & 100.0 \\
\hline 1996 & & & & & $12 / 6-7^{a}$ & -7.5 & -20 & 39.9 & 8.1 \\
\hline $\begin{array}{l}1990 \\
1 / 5-6\end{array}$ & -2.3 & 2 & 20.6 & 4.5 & $12 / 16-17$ & -4.2 & -4 & 29.4 & 11.0 \\
\hline $1 / 8-9^{a}$ & -4.9 & -11 & 28.1 & 3.8 & 1997 & & & & \\
\hline $1 / 13$ & -5.9 & -26 & 21.4 & $\begin{array}{r}0.0 \\
12.0\end{array}$ & $1 / 5-7^{a}$ & -6.8 & -22 & 32.6 & 6.5 \\
\hline $1 / 14-15$ & -6.0 & -29 & 19.4 & 24.0 & $1 / 30-31$ & -8.7 & -42 & 27.8 & 11.0 \\
\hline $1 / 17-18^{\mathrm{a}}$ & -7.4 & -41 & $\begin{array}{l}19.4 \\
18.2\end{array}$ & $\begin{array}{r}24.0 \\
3.9\end{array}$ & $2 / 8-11$ & -4.7 & -16 & 21.6 & 6.0 \\
\hline $1 / 31-2 / 3^{a}$ & -5.2 & -6 & 35.6 & 4.0 & $2 / 26-28$ & -1.3 & 5 & 16.3 & 13.5 \\
\hline $2 / 5-6^{a}$ & -1.5 & 7 & 19.1 & 1.4 & $3 / 6$ & -2.0 & 7 & 23.1 & 8.5 \\
\hline $2 / 8-10^{a}$ & -8.6 & -40 & 28.7 & $\begin{array}{r}1.4 \\
12.5\end{array}$ & $3 / 10$ & -2.5 & -3 & 17.7 & 38.5 \\
\hline $2 / 24-25$ & -5.1 & -13 & 27.7 & 6.5 & $3 / 12-16$ & -2.7 & -7 & 14.1 & 86.0 \\
\hline $2 / 29$ & -4.4 & 3 & 38.0 & 8.5 & $3 / 26$ & -2.4 & -4 & 15.6 & 5.5 \\
\hline $3 / 7$ & -1.4 & 12 & 23.2 & 1.5 & $3 / 28-29$ & -4.7 & -23 & 15.0 & 9.0 \\
\hline $3 / 14-15$ & -7.3 & -39 & 19.1 & 88.0 & $4 / 1-5$ & -3.5 & -13 & 15.2 & 97.5 \\
\hline $3 / 16-17$ & -3.1 & -7 & 17.6 & 72.0 & $4 / 18$ & -2.8 & 0 & 22.1 & 9.5 \\
\hline $3 / 21-22$ & -5.5 & -25 & 18.8 & 78.0 & $4 / 21-22$ & -5.0 & -19 & 21.0 & 152.0 \\
\hline $3 / 24$ & -2.4 & 2 & 21.6 & 2.0 & $4 / 27-28$ & -6.8 & -35 & 19.1 & 18.0 \\
\hline $3 / 28-30$ & $\begin{array}{l}-2.4 \\
-2.9\end{array}$ & $\begin{array}{r}2 \\
-9\end{array}$ & $\begin{array}{l}21.0 \\
14.1\end{array}$ & $\begin{array}{r}2.0 \\
22.0\end{array}$ & $5 / 2-3$ & -8.4 & -51 & 16.2 & 12.0 \\
\hline $4 / 6$ & -1.0 & 20 & $\begin{array}{l}14.1 \\
28.3\end{array}$ & $\begin{array}{r}22.0 \\
1.0\end{array}$ & & & & & \\
\hline asnow & & & & & & & & & \\
\hline
\end{tabular}




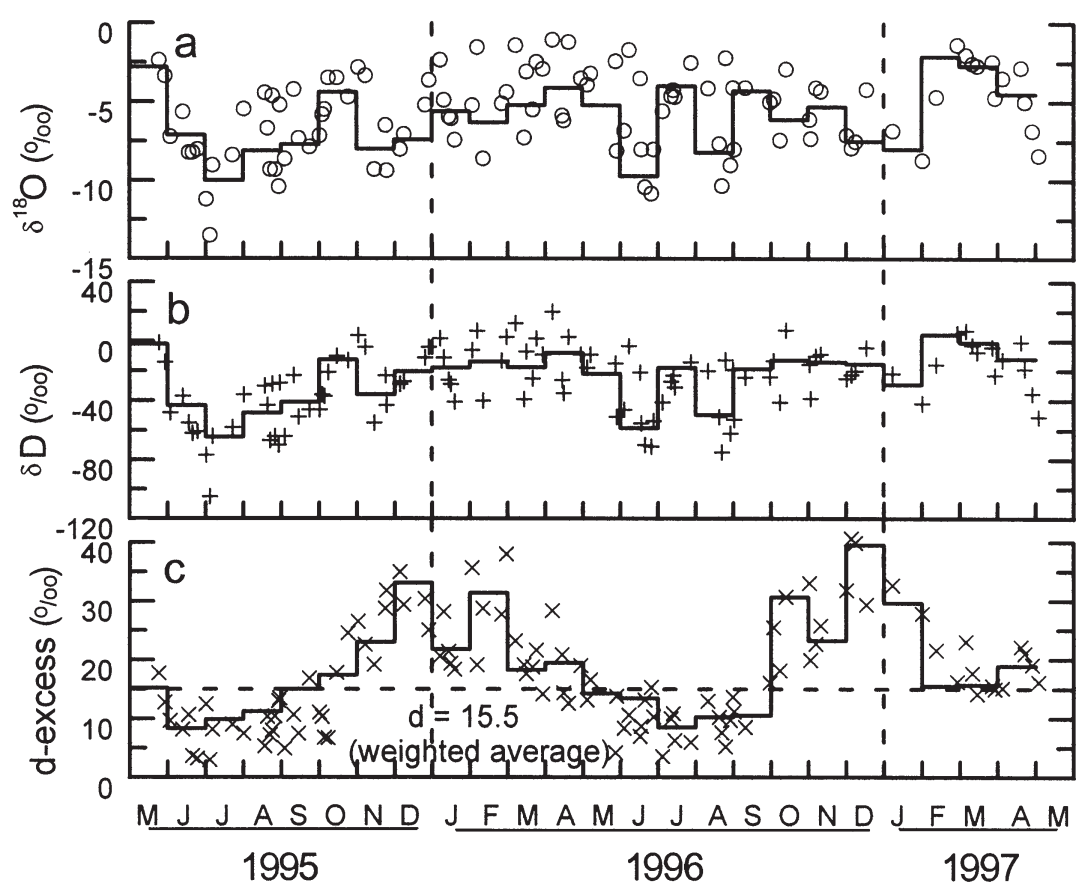

Fig. 5. (a) Oxygen isotopic composition, (b) hydrogen isotopic composition and (c) d-value of precipitation at Jeju Island from May 1995 to May 1997. Solid lines represent the monthly weighted average isotopic compositions

spectively). At mid-latitudes, both temperature and rainfall amount are important factors controlling the final isotopic composition of precipitation (Dansgaard 1964, Lawrence \& White 1991).

During the study period (May 1995 to May 1997), the isotopic composition of precipitation was quite variable, with $\delta^{18} \mathrm{O}$ ranging from -13.5 to $-1.0 \%$, and $\delta \mathrm{D}$ from -105 to $+20 \%$ (see Table 1, Fig. 5). The weighted mean value for all data is $-7.1 \%$ for $\delta^{18} \mathrm{O}$ and $-41 \%$ o for $\delta \mathrm{D}$.

On average, higher $\delta^{18} \mathrm{O}$ - and $\delta \mathrm{D}$-values actually occur in winter. To assess the physical mechanism for this, air parcel trajectories were back calculated for precipitation events with the highest $5 \mathrm{~d}$-values. Collectively, the average isotopic concentrations of these rainfall events were $-6.6 \%$ and $-15 \%$ for $\delta^{18} \mathrm{O}$ and $\delta \mathrm{D}$, respectively. In all 5 cases, the modeled trajectories show that air masses originate over NE Asia and pass over the Yellow Sea before reaching Jeju Island. A representative example of such a path is provided for 5 December 1996 (Fig. 6a). As the dry air passes over the relatively warmer water,

(mm), and $\delta_{i}=$ isotopic value of bulk precipitation event.

When discussing stable isotopic data of precipitation, it is important to identify the mechanisms that govern the final isotopic composition. Generally, the stable isotopic composition of precipitation decreases with decreasing temperature, and with increasing latitude, elevation, and rainfall amount (the so-called temperature, latitude, altitude, and amount effects, reevaporation from the sea surface doubles the precipitable water content to over $8 \mathrm{~kg} \mathrm{~m}^{-2}$ of air at the study site (Fig. 6b). Thus, the isotopically enriched winter precipitation is a function of oceanic moisture close to Korea and Japan.

The $\delta^{18} \mathrm{O}$ - and $\delta \mathrm{D}$-values for summer precipitation (June to September) are generally lower than those for other seasons (Fig. 5). This seems to reflect differences
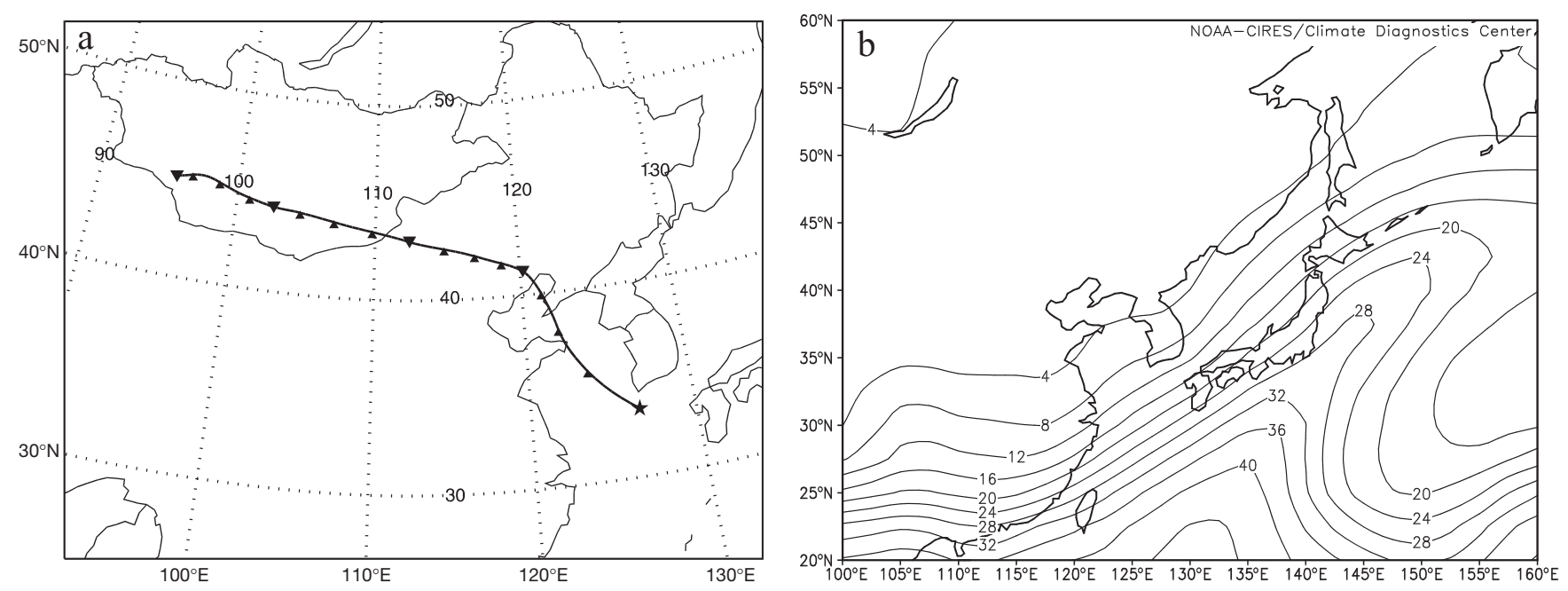

Fig. 6. Winter air masses: (a) air parcel back trajectory for $96 \mathrm{~h}$ leading up to 5 December 1996 and (b) precipitable water (kg $\mathrm{m}^{-2}$ ) for 5 December 1996 
in the amount of rainfall (Dansgaard 1964). This amount effect has been found all the year around at most tropical stations, and in the summer at many midlatitude locations (Lawrence \& White 1991, Rozanski et al. 1993). The isotopically depleted summer precipitation in NE Asia is attributed to tropical cyclones, which include tropical storms and typhoons. Lawrence \& Gedzelman (1996) have monitored stable isotopic compositions of tropical cyclone rains in Texas, USA, and found that tropical cyclone rains had anomalously lower stable isotope ratios than other tropical and summer precipitation systems. Some of the low summer values in this study were from such tropical storms. For example, during the summer months of 1995, 3 tropical cyclones passed over the study site (Typhoons Janis on July 1-8, Faye on July 22-24, and Ryan on September 21-23). Of these, Janis produced a huge amount of rainfall (approximately $620 \mathrm{~mm}$ over $8 \mathrm{~d}$ ) with the most depleted isotopic composition of the study period $\left(-13.5 \%\right.$ for $\delta^{18} \mathrm{O}$ and $-105 \%$ for $\left.\delta \mathrm{D}\right)$.

For summer precipitation a weak inverse relationship exists between isotopic composition and precipitation amount (P) (not shown). Least-square lines fitted to these data are:

$$
\begin{aligned}
\delta^{18} \mathrm{O}= & (-0.0199 \pm 0.0053) \mathrm{P}-(5.90 \pm 0.44) \\
& \left(\mathrm{r}^{2}=0.26, \mathrm{n}=43\right) \\
\delta \mathrm{D}= & (-0.143 \pm 0.044) \mathrm{P}-(38.7 \pm 3.65) \\
& \left(\mathrm{r}^{2}=0.20, \mathrm{n}=43\right)
\end{aligned}
$$

These equations mean that $\delta^{18} \mathrm{O}$-values change by $-1.99 \%$ and $\delta \mathrm{D}$-values by $-14.3 \%$ per $100 \mathrm{~mm}$ of rainfall. Yurtsever \& Gat (1981) found that monthly average $\delta^{18} \mathrm{O}$-values of precipitation for island stations in the equatorial zone change by $-1.5 \%$ for a $100 \mathrm{~mm}$ increase in precipitation amount. Such an amount effect at Jeju Island is related to the hot and humid conditions in summer which are typically accompanied by downpours. Dansgaard (1964) showed that such downpours tend to dramatically decrease the heavy isotopes of the cloud at the beginning of precipitation, resulting in isotope-depletion of precipitation at a later stage.

As shown in Fig. 7, all of the oxygen and hydrogen isotopic data, regardless of season, define a local meteoric water line:

$$
\begin{aligned}
\delta \mathrm{D}= & (8.38 \pm 0.33) \delta^{18} \mathrm{O}+(19.15 \pm 0.85) \\
& \left(\mathrm{r}^{2}=0.85, \mathrm{n}=109\right)
\end{aligned}
$$

However, regression lines can also be drawn to describe the isotopic data for different seasons (see Fig. 7). A regression line for summer (June to September) precipitation is:

$$
\begin{aligned}
\delta \mathrm{D}= & (7.94 \pm 0.20) \delta^{18} \mathrm{O}+(8.87 \pm 1.46) \\
& \left(\mathrm{r}^{2}=0.98, \mathrm{n}=43\right)
\end{aligned}
$$

and for winter (November to February) precipitation:

$$
\begin{aligned}
\delta \mathrm{D}= & (6.88 \pm 0.52) \delta^{18} \mathrm{O}+(20.79 \pm 3.17) \\
& \left(\mathrm{r}^{2}=0.86, \mathrm{n}=30\right)
\end{aligned}
$$

Most of the precipitation samples in spring and fall plot between these 2 lines. The isotopic composition for winter precipitation shows much larger scatter than that for summer precipitation. Both slope and intercept for summer precipitation are virtually the same as the Global Meteoric Water Line (GMWL) defined by Craig (1961), whereas the slope of 6.88 of winter precipitation is considerably lower than that for the GMWL. Such a flat slope can be produced by kinetic fractionation effects resulting from non-equilibrium vapor formation at its place of origin and/or by re-evaporation of falling rain drops. The trajectories of winter air masses pass over the Yellow Sea before arriving at Jeju Island (Fig. 6a) and the large increases in atmospheric moisture along this path (Fig. 6b) indicate that nonequilibrium vapor formation from net evaporation is the dominant reason for the flat slope. Secondary reevaporation of rainfall is unlikely in winter due to cold temperatures. In addition, deuterium excess values for winter precipitation are uniformly $>15 \%$, and d-values $>10 \%$ are incompatible with secondary re-evaporation of rainfall because this tends to decrease the deuterium excess values. The stable isotope values for winter precipitation are generally high because the extent of Rayleigh distillation is small.

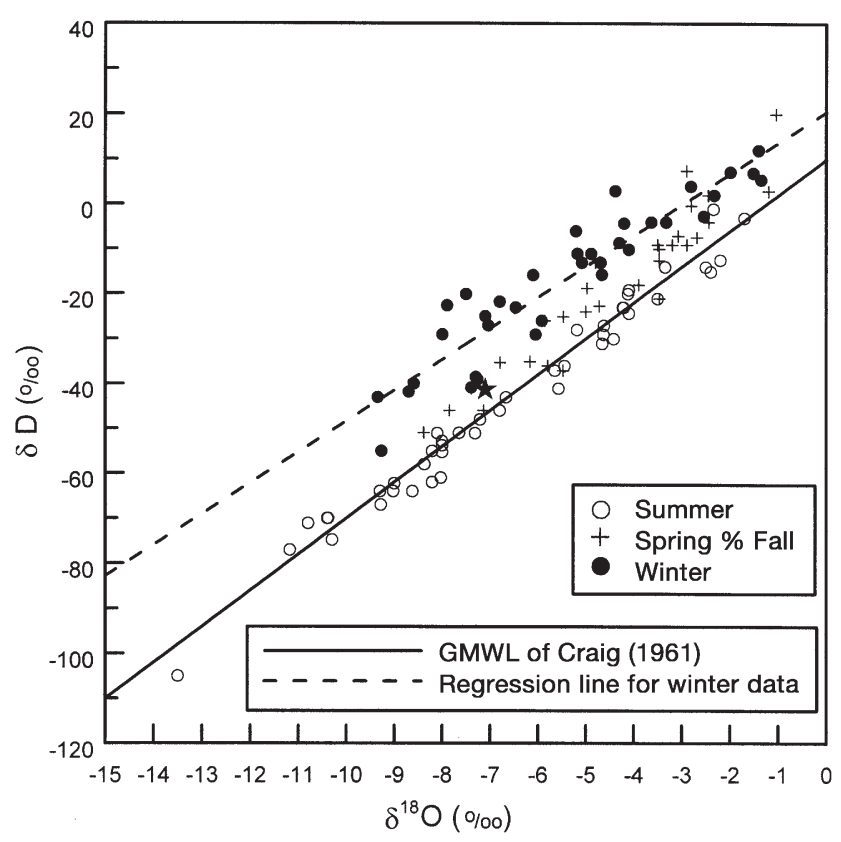

Fig. 7. Plot of $\delta \mathrm{D}$ versus $\delta^{18} \mathrm{O}$ in precipitation samples from Jeju Island. GMWL is the global meteoric water line defined by Craig (1961). The star in the center represents a weighted average of all data 


\subsection{Deuterium excess (d-) values}

The deuterium excess values at Jeju Island range from 3.0 to $40.6 \%$ with a weighted average of $15.5 \%$, and they display a winter-summer cyclic variation (Fig. 5). The d-values for winter precipitation deviate significantly from the global average of $10 \%$ (Fig. 7). The values of deuterium excess for summer precipitation $(\mathrm{d}=\sim 10 \%)$ can be clearly distinguished from winter precipitation ( $>$ $>15 \%$ ) (Fig. 7). Deuterium excess values for spring and fall seasons are transitional.

Such distinct seasonal d-values can be explained by the differing sources of moisture affecting Jeju Island. In winter, the higher deuterium excess values reflect the origin of the prevailing air masses in Mongolia and the Lake Baikal region of Siberia. This region is the source for some of the most well developed continental high-pressure air masses of NE Asia (Kwon 1985). The IAEA/WHO stable isotopic data set indicates that moisture in this region has d-values close to $10 \%$ (Qiqihar, Fig. 2) to the north of the Korean Peninsula and somewhat more positive values further east (Wulumuqi, Fig. 2). We hypothesize that the Siberian air mass at its site of origin formed in part under near equilibrium conditions and was modified by picking up additional moisture as it migrated southeast toward the Korean Peninsula and Japan. This is likely to occur over the Yellow Sea and East Sea (Sea of Japan) when the air mass interacts with the relatively warm sea.

As a result of such an air-sea interaction, the air mass becomes unstable and this results in heavy precipitation on the coast of the Korean Peninsula and Japan. As we will illustrate with a subsequent case study, the high d-values support the idea that the uptake of moisture over the sea involves rapid kinetic isotope fractionation processes that impart an enriched d-value to the air mass that produces rainfall throughout Korea.

In summer, the lower deuterium excess values reflect the hot and humid characteristics of the North Pacific. The trajectories of rainfall events with the lowest 5 d-values illustrate that the source regions for these air masses are in the South China Sea or the tropical North Pacific Ocean. The trajectory for 5 July 1995 is representative and shows that the air originated in the South China Sea and migrated over eastern China and the Yellow Sea before arriving at Jeju Island (Fig. 8). Based on the slope and intercept of the regression line for summer precipitation (Eq. 4), which is virtually identical to Craig's GMWL, the North Pacific cloud masses probably formed by much slower evaporation.

A case study of 2 precipitation events with extreme d-values illustrates the relationship between the $\mathrm{d}$-value and the meteorological conditions in the source region. Precipitation on December 4, 1996 had one of the

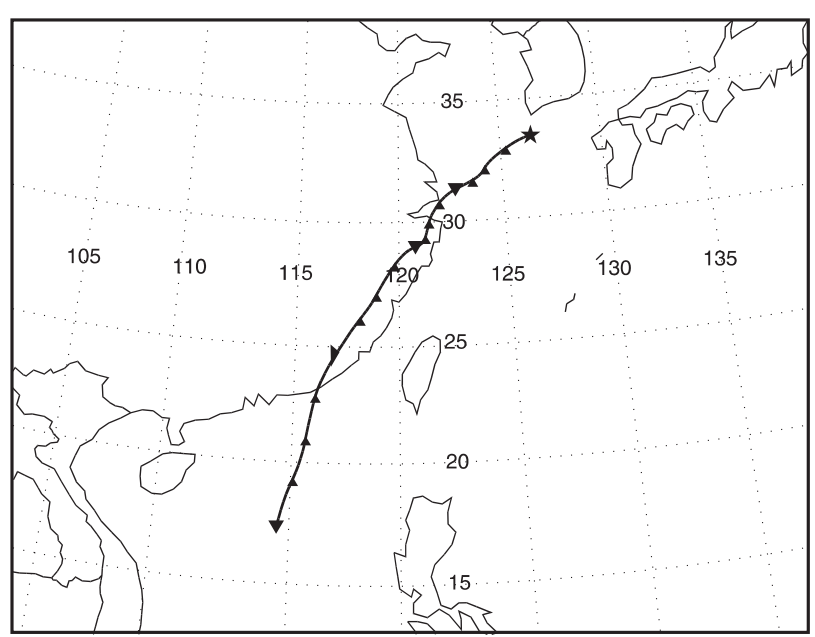

Fig. 8. Summer air masses: summer air parcel back trajectory for $96 \mathrm{~h}$ leading up to 5 July 1995

highest d-values recorded (40.6\%) of any of the samples over the 3 yr study period. Characteristic of the winter Asian monsoon, a strong high pressure center was located over the Asian continent. The anticyclonic circulation advects a north or northwesterly flow over Jeju Island, bringing continental polar air (Fig. 9a). A trajectory of the air mass shows that it migrated out of Northern China, just east of Mongolia and moved southward over the Yellow Sea towards Jeju Island (Fig. 9b). The source region for this air mass is a cold, snow covered continental area (Fig. 9c,d). The water content of the snowpack, exceeding $24 \mathrm{~mm}$, is sufficiently extensive and deep to cover the surface. In addition, temperatures across the region were well below freezing $\left(<-20^{\circ} \mathrm{C}\right.$, or $\left.<253 \mathrm{~K}\right)$. The low air temperatures mean that there was little energy available for evaporation or sublimation of snow. Also, there was little net evaporation or sublimation from the surface towards the atmosphere in the air mass source region because relative humidities exceeded $80 \%$ (Fig. 9e). As a result, the air was very dry with specific humidity values $<2 \mathrm{~g}$ $\mathrm{kg}^{-1}$ (Fig. 9f). The north to south path over the Yellow Sea allowed for a greater fetch and thus more time for the moisture and temperature characteristics of the air mass to be modified. The warm water rapidly evaporated into the overlying dry air mass and increased the specific humidity values from 2 to $10 \mathrm{~g} \mathrm{~kg}^{-1}$ (Fig. 9f). This moisture source lead to rapid isotope fractionation and a greatly enriched d-value in the air mass that produced rainfall over the study site.

A very different meteorological situation occurred on 21 June, 1995 with a d-value of 3.7\%o. Low pressure centered over eastern China (Fig. 10a) brought southwesterly winds and advected warm, moist air from the North Pacific. A trajectory of the air parcel shows that it 
a
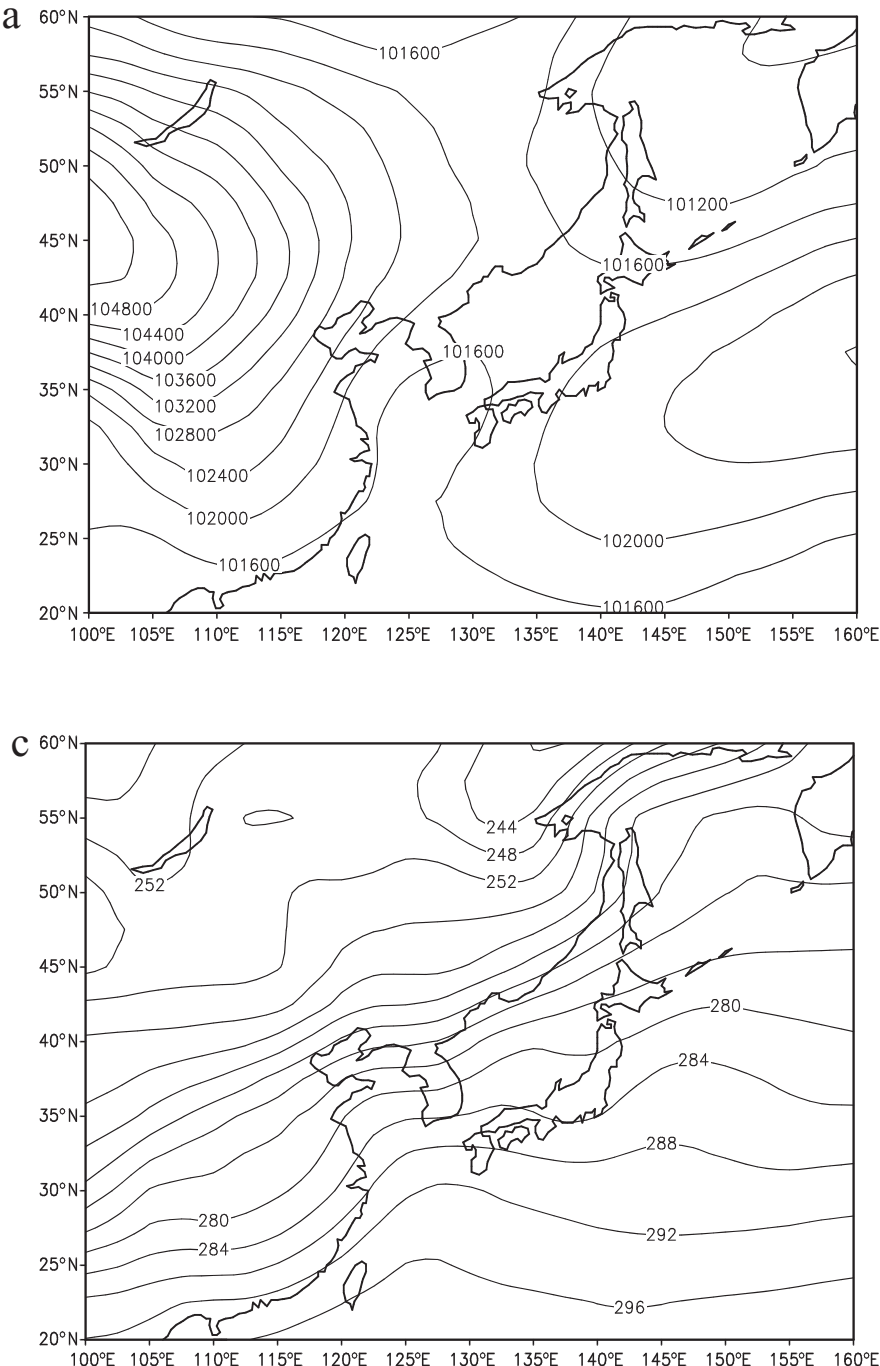

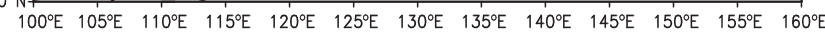

b

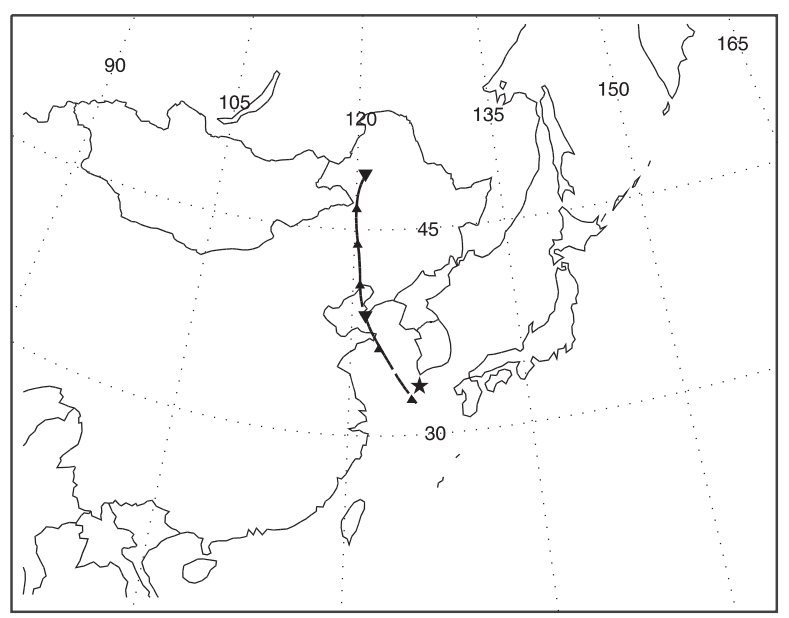

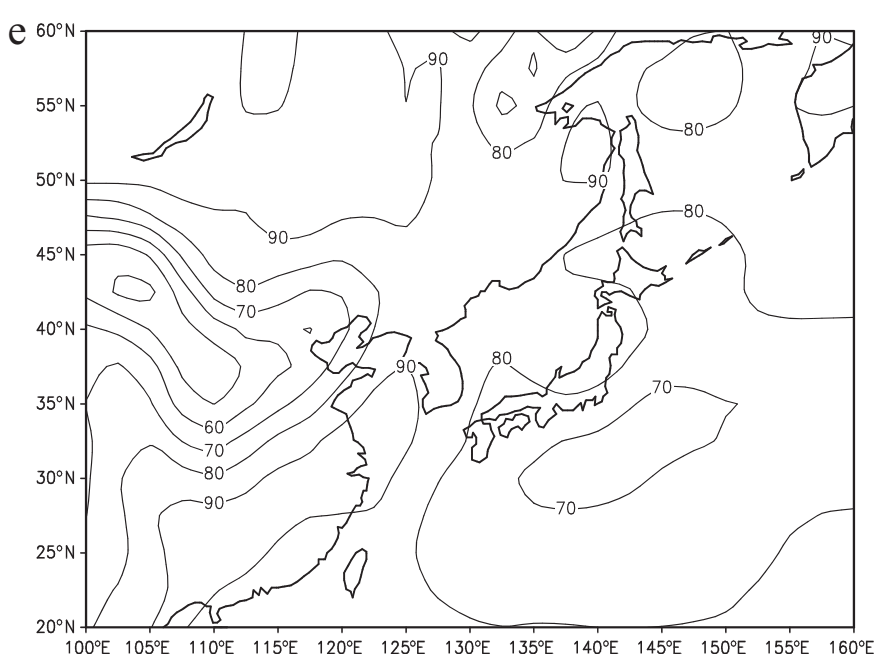
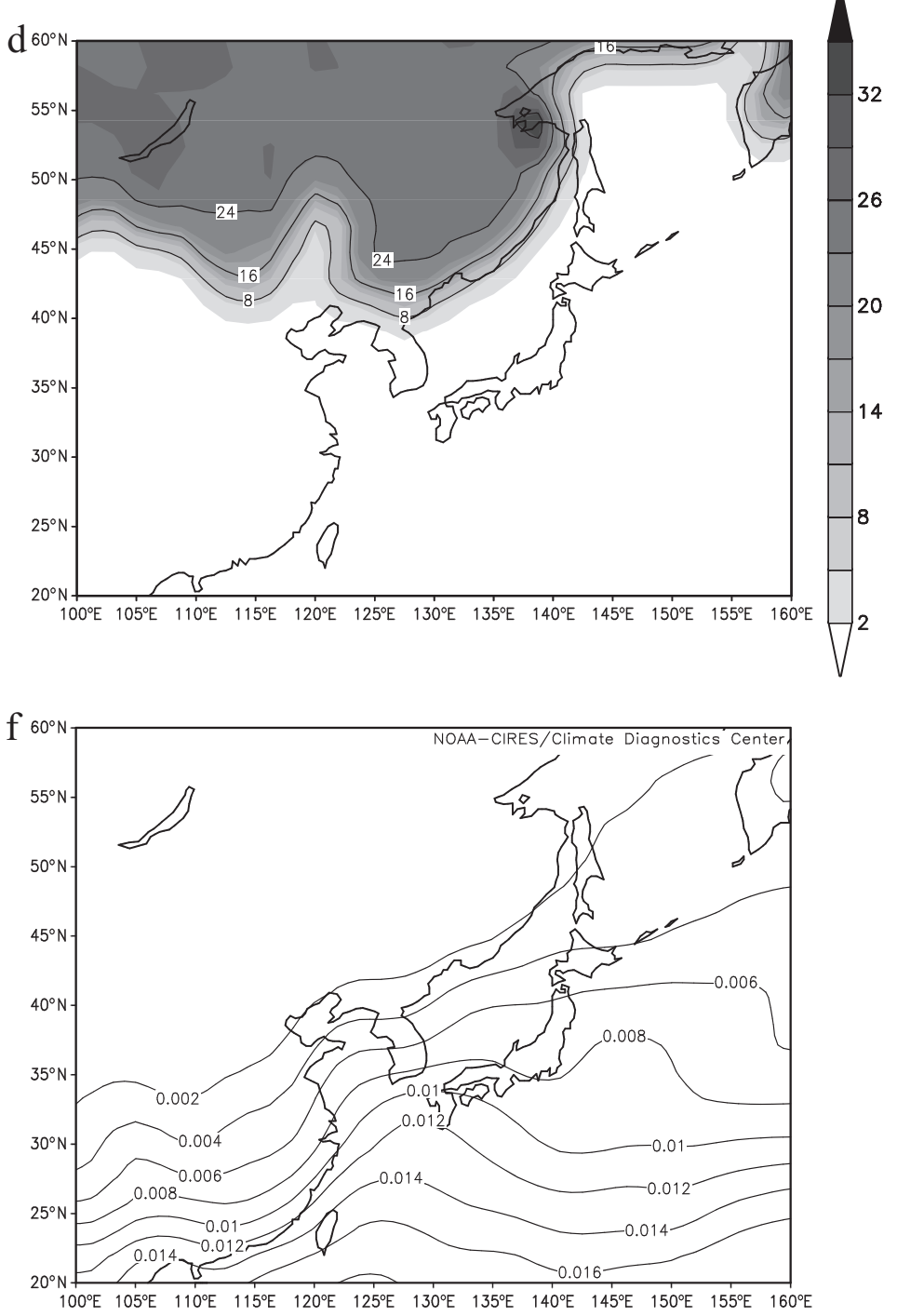

Fig. 9. Surface meteorological values for 4 December 1996: (a) sea-level pressure (Pa), (b) air parcel back trajectory for 96 h, (c) surface temperature $(\mathrm{K})$, (d) snow water equivalent $\left(\mathrm{kg} \mathrm{m}^{-2}\right)$, (e) relative humidity (\%) and (f) specific humidity (kg $\left.\mathrm{kg}^{-1}\right)$ 

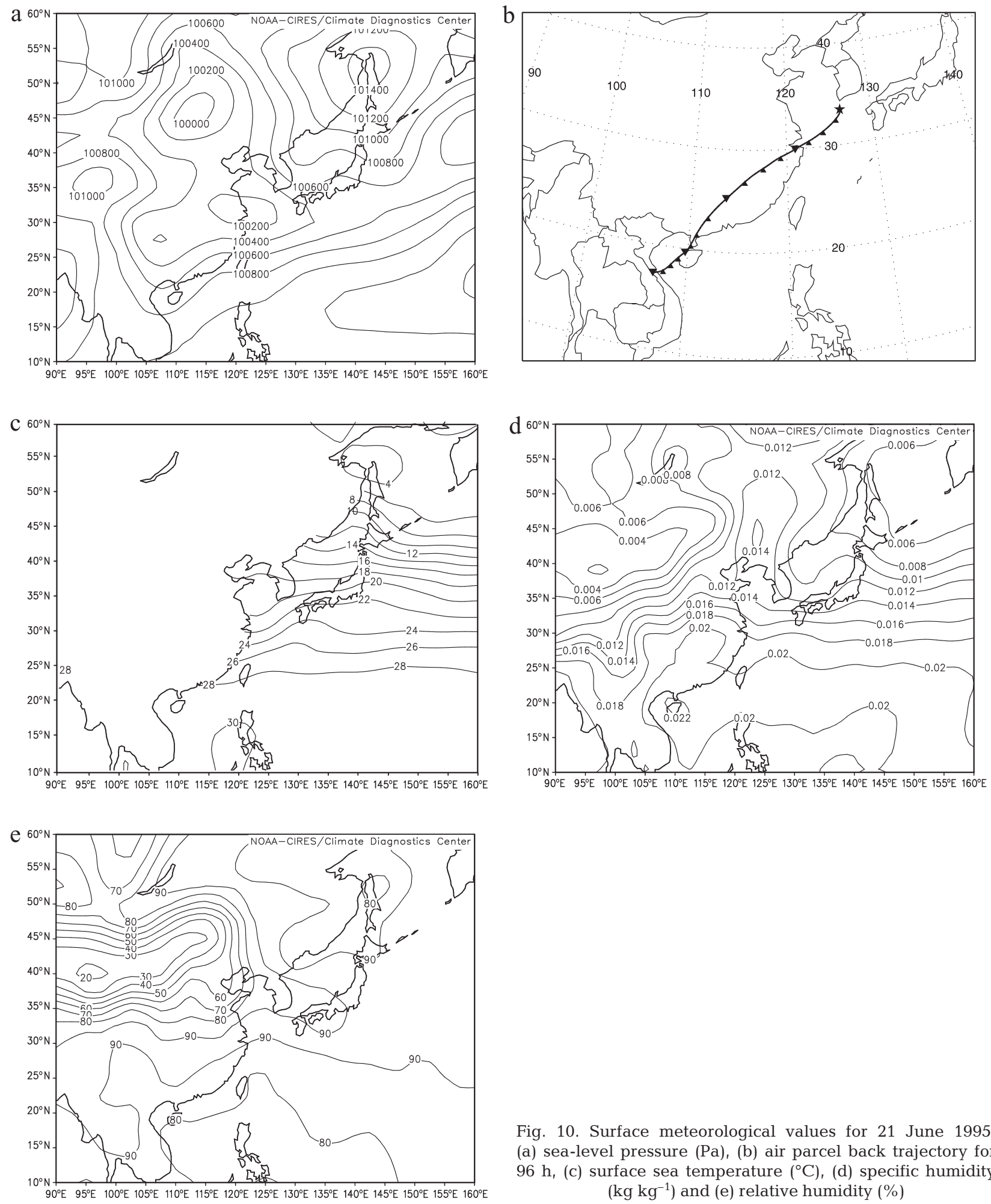

Fig. 10. Surface meteorological values for 21 June 1995: (a) sea-level pressure (Pa), (b) air parcel back trajectory for $96 \mathrm{~h}$, (c) surface sea temperature $\left({ }^{\circ} \mathrm{C}\right)$, (d) specific humidity $\left(\mathrm{kg} \mathrm{kg}^{-1}\right)$ and (e) relative humidity (\%)

originated in the South China Sea, migrated over eastern China and across the Yellow Sea before arriving at Jeju Island (Fig. 10b). The air mass formed over warm waters with SSTs $>28^{\circ} \mathrm{C}$ (Fig. 10c) and high specific

humidity values of over $20 \mathrm{~g} \mathrm{~kg}^{-1}$ (Fig. 10d). The air mass of the source region was near its saturation point (relative humidity values $>80 \%$ ) and very limited net evaporation to the atmosphere was occurring (Fig. 10e). 


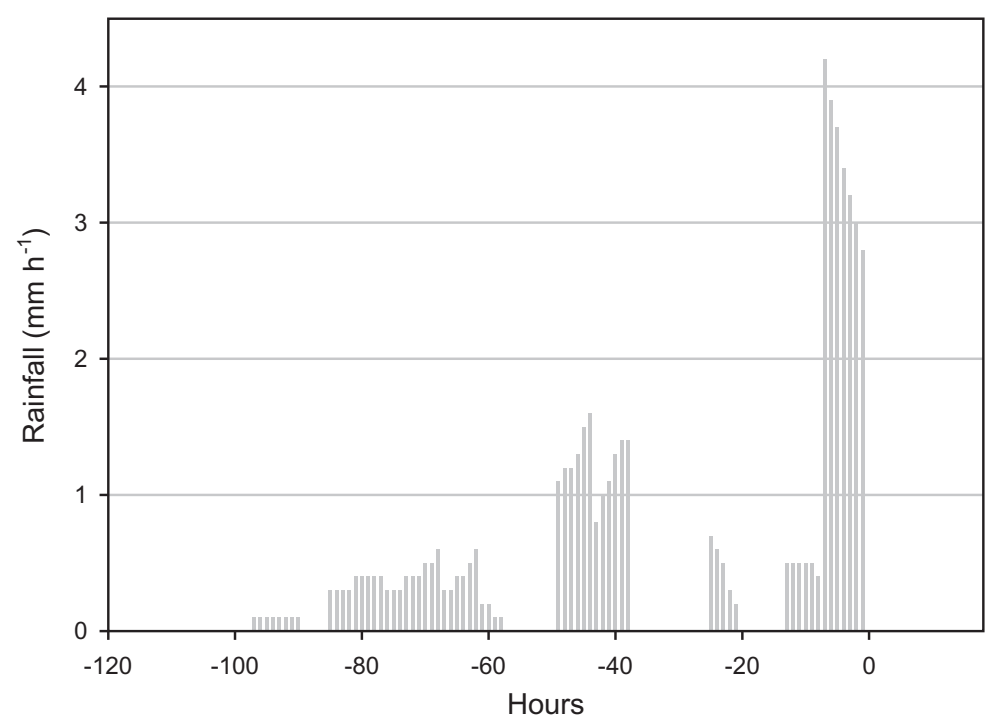

Fig. 11. Precipitation rates at Jeju Island on 21 June 1995
Japan and eastward to Korea and inland parts of NE China.

To understand this regional pattern, more detailed stable oxygen and hydrogen isotopic studies were made of distinct, individual rainfall events from 1995 to 1997 at Jeju Island, $100 \mathrm{~km}$ south of the Korean Peninsula. The isotopic data show a large isotopic variation ranging from -13.5 to $-1.0 \%$ o for $\delta^{18} \mathrm{O}$ and -105 to $+20 \%$ for $\delta \mathrm{D}$. These data correlated little with temperature. However, the deuterium excess values clearly display a seasonal variation correlated with seasonal climatic changes. In particular, values of deuterium excess for summer precipitation (d 10\%) can be clearly distinguished from winter precipitation ( $\mathrm{d}>\sim 15 \%$ ). The $\delta^{18} \mathrm{O}$ and $\delta \mathrm{D}$ values for summer precipitation show an amount effect and plot along a line defined by $\delta \mathrm{D}=(7.94 \pm 0.20) \delta^{18} \mathrm{O}+(8.87 \pm 1.46)$

Such conditions produce low d-values. The isotopic concentration of the rainfall decreased as the specific humidity decreased from 20 to $14 \mathrm{~g} \mathrm{~kg}^{-1}$ (Fig. 10d) due to nearly continuous rainfall as the air parcel moved from the South China Sea towards Jeju Island (Fig. 11). The nature of the precipitation mechanism is especially important here because the tropical precipitation systems that prevail during the summer tend to have heavy rainfall that is isotopically depleted (Fig. 11).

Gat \& Carmi (1970) proposed a similar model to explain the deuterium excess values $(>15 \%$ ) of precipitation in the Eastern Mediterranean region. They suggested that high d-values there resulted when air masses with d-values of $<12 \%$ originating in northern Europe became enriched due to rapid evaporation from the Eastern Mediterranean Sea as the air mass migrated to the southeast. Fritz et al. (1987) also noted that $\mathrm{d}$-values of precipitation in Canada strongly depend on the meteorological regime, but generally are lower in summer than in winter. They attributed these differences to the prevalence of tropical air masses from the Pacific with lower d-values during summer and Arctic air masses with relatively high d-values during winter.

\section{SUMMARY}

The original studies of Dansgaard (1964) using the 1961-62 IAEA/WMO data set indicated that the seasonal pattern in d-values of monthly average rainfall at Tokyo, Japan, reflected differing sources of moisture. Our examination of a much more complete set of data from the IAEA/WMO website for sites in NE Asia confirms Dansgaard's original observations and further indicates that this pattern extends to other sites in $\left(\mathrm{r}^{2}=0.98, \mathrm{n}=43\right)$, very similar to Craig's GMWL, reflecting near equilibrium isotope fractionation in the source area of the Northern Pacific Ocean. In contrast, winter precipitation plots along a line defined by $\delta \mathrm{D}=(6.88 \pm$ $0.52) \delta^{18} \mathrm{O}+(20.79 \pm 317)\left(\mathrm{r}^{2}=0.86, \mathrm{n}=30\right)$, with a slope smaller than 8 and intercept larger than 10, which strongly indicates that winter precipitation is caused by the cold dry polar air masses moving southward over the Yellow Sea and picking up most of their moisture from ditions.

The seasonally distinct d-values reflect the diverse air masses and moisture sources that affect the island during the summer and winter seasons. Jeju Island is strongly affected by the Asian monsoon. In the winter, a strong continental high pressure system develops and advects continental polar air formed over a land surface that is largely covered by snow. Before reaching the study site at Jeju Island, these air masses gain moisture as they pass over the Yellow Sea. Under such environmental conditions, the precipitation tends to be isotopically enriched. During the summer, a thermally driven low pressure system develops over the Asian continent, leading to cyclonic circulation and a southerly flow over Jeju Island. This drives warm, moist maritime tropical air masses over the island. Moisture during these times tends to be isotopically depleted in its source region and due to mechanisms associated with rainfall amount.

Acknowledgements. We thank the 2 anonymous reviewers for their critical review of the manuscript. The editorial handling of Robert Davis is very much appreciated. This work was supported by a grant (code 3-2-1) from the Sustainable Water Resources Research Center of 21st Century Frontier Research Program. rapid evaporation processes under non-equilibrium con- 


\section{LITERATURE CITED}

Clark ID, Fritz P (1997) Environmental Isotopes in Hydrogeology. Lewis Publishers, New York

Coleman ML, Shepherd TJ, Durham JJ, Rouse JE, Moore GR (1982) Reduction of water with zinc for hydrogen isotope analysis. Anal Chem 54:993-995

Craig H (1961) Isotopic variations in meteoric waters. Science 133:1702-1703

Dansgaard W (1964) Stable isotopes in precipitation. Tellus $16: 436-468$

Draxler RR (1999) HYSPLIT_4 users guide, version 4.5. NOAA Tech Memo ERL ARL-230

Ehhalt D, Knott K, Nagel JF, Vogel JC (1963) Deuterium and oxygen 18 in rain water. J Geophys Res 68:3775-3780

Epstein S, Mayeda TK (1953) Variation of $\mathrm{O}^{18}$ content of waters from natural sources. Geochim Cosmochim Acta $4: 213-224$

Fritz P, Drimmie RJ, Frape SK, O'Schea K (1987) The isotopic composition of precipitation and groundwater in Canada. In: Isotope Techniques in Water Resources Development, IAEA Symp 299, Vienna, p 539-550

Gat JR, Carmi I (1970) Evolution of the isotopic composition of atmospheric waters in the Mediterranean Sea area. J Geophys Res 75:3039-3048

Gat JR, Dansgaard W (1972) Stable isotope survey of the fresh water occurrences in Israel and the northern Jordan rift valley. J Hydrol 16:177-212

Gedzelman SD, Lawrence JR, White JWC, Smiley D (1987) The isotopic composition of precipitation at Mohonk Lake, New York: the amount effect. J Geophys Res 92: 1033-1040

Kalnay E, Kanamitsu M, Kistler R, Collins W and 17 others

Editorial responsibility: Robert Davis,

Charlottesville, Virginia, USA
(1996) The NCEP/NCAR Reanalysis 40-year Project. Bull Am Meteorol Soc 77:437-471

Kim KH, Nakai N (1988) Isotopic compositions of precipitations and groundwaters in South Korea. J Geol Soc Korea 24:37-46 (in Korean with English abstract)

Kwon HJ (1985) Natural Geography. Bummoonsa, Seoul (in Korean)

Lawrence JR, Gedzelman SD (1996) Lower stable isotope ratios of tropical cyclone rains. Geophys Res Lett 23: $527-530$

Lawrence JR, White JWC (1991) The elusive climate signal in the isotopic composition of precipitation In: Taylor HP Jr, O'Neil JR, Kaplan IR (eds) Stable isotope geochemistry: a tribute to Samuel Epstein. Geochem Soc Spec Publ No 3:169-185

Lawrence JR, Gedzelman SD, White JWC, Smiley D, Lazov P (1982) Storm trajectories in eastern US D/H isotopic composition of precipitation. Nature 296:638-640

Lee KS, Chang BU (1994) Oxygen and hydrogen isotopic composition of precipitation in Taejeon and Seoul, Korea. J Geol Soc Korea 30:475-481 (in Korean with English abstract)

Reynolds RW (1988) A real-time global sea surface temperature analysis. J Climate 1:75-86

Rozanski K, Araguas-Araguas L, Gonfiantini R (1993) Isotopic patterns in modern global precipitation. In: Swart PK, Lohmann KC, McKenzie J, Savin S (eds) Climate change in continental isotopic records. American Geophysical Union, Geophys Monogr 78:1-36

Yurtsever Y, Gat JR (1981) Atmospheric waters. In: Gat JR, Gonfiantini R. (eds) Stable Isotope Hydrology: Deuterium and oxygen-18 in the water cycle. IAEA Tech Rep Ser 210:103-142

Submitted: July 26, 2001; Accepted: September 9, 2002 Proofs received from author(s): November 5, 2002 